\title{
Research on the Carbon Emissions of Beijing Residents Based on the Input-Output Model
}

\author{
Yifei Zhang ${ }^{1,2}$, Yalin Lei ${ }^{1,2 *}$ \\ ${ }^{1}$ School of Humanities and Economic Management, China University of Geosciences, \\ Beijing, 100083, P.R. China \\ ${ }^{2}$ Key Laboratory of Carrying Capacity Assessment for Resource and Environment, Ministry of Land and Resources, \\ Beijing, 100083, P.R.China
}

Received: 31 January 2017

Accepted: 12 March 2017

\begin{abstract}
China is facing increasing pressure on international emissions. As the capital of China, Beijing should set an example for carbon emissions. Previous studies on carbon emissions mainly focused on household size and changes in household consumption structure during urbanization. The input-output method is mainly used, but the total output of each department is used to measure the intensity of $\mathrm{CO}_{2}$ emissions, so that the middle input and added value among the sectors are included, which leads to a large measurement result. Based on the input-output model, the paper chooses the latest input-output table of Beijing in 2012 and calculates the carbon emissions of residents in Beijing in 2012, which calculates the $\mathrm{CO}_{2}$ emission intensity by using the added value that avoids the problem of double counting. The results show that the total carbon emissions of Beijing residents is 762.948 million tons, of which the direct consumption energy of urban residents is mainly gasoline and heat, while that of rural residents is mainly coal and electricity. Indirect carbon emissions of residential consumption are divided into eight consumption categories. Among them, $57.2 \%$ and $18.9 \%$ were in transportation and housing, respectively. According to the above conclusions, this paper makes some recommendations.
\end{abstract}

Keywords: residential consumption, direct emissions, indirect emissions, input-output model

\section{Introduction}

Global climate change has become the most pressing environmental problem today. As a big country of energy consumption and a big emitter of greenhouse gases, China is exposed to more and more pressure of international emission reduction. How to realize the win-win relationship between development and energy savings,

*e-mail: leiyalin@cugb.edu.cn as well as the reduction of emissions, is of great significance to China's overall situation of sustainable development. China has promised to reduce carbon intensity of $40-50 \%$ by 2020 , and to use it as a binding indicator in the long-term planning of national economic and social development [1]. This shows that China, as a developing country, is determined to develop a lowcarbon economy and protect the environment. While Beijing, as its political and cultural center, should set an example in this regard. At present, the energy structure of Beijing is still mainly on carbon consumption. In recent years, with the rapid development of the economy and 
the continuous expansion of city scale, the environmental problems are becoming more and more serious. Frequent heavy haze phenomenon has caused much attention to carbon emissions. According to the Chinese Ministry of Environmental Protection Institute of Environmental Planning data, heavy pollution in Beijing in 2015 accounted for $12-14 \%$ of the total number of days, which means that about 47 days of 2015 were polluted weather. Today Beijing is striving to be an international metropolis, which not only requires rapid economic development but also requires their attention to the living environment for residents, and makes for sustainable economic and environmental development.

The consumption behavior of residents will affect 45$55 \%$ of total energy consumption. While a key measure of human living standards, energy utilization is closely related to all production and living processes and has a wide range of environmental impacts [2]. Previous studies on carbon emissions focused on basic research of industrial carbon emissions, and analysis of carbon emissions from economic development, energy structure, and other aspects. But the increasing use of private cars and frequent travel, mounting purchases of household appliances, and improvement of living conditions have resulted in the rapid growth of consumption carbon emissions. Residential consumption of carbon emissions has become the second largest carbon emissions sector next to the industrial sector [2]. The control of carbon emissions of residential life, in order to achieve lowcarbon consumption, has become an important part and an inevitable choice of low-carbon development. Therefore, research on urban and rural residents' consumption of carbon emissions is of great significance to promote the sustainable consumption of residents and to find new ways to save energy and reduce emissions. At the same time, the study of Beijing residents' carbon emissions is also necessary for the surrounding provinces and even the all Chinese low-carbon development.

Previous studies on energy consumption and carbon emissions are more concentrated in the field of industrial production and the relationship between carbon emissions and economic growth [3-9] - a largely ignored role in promoting energy consumption and carbon emissions, while international studies of household and residential energy consumption have gained gradually in recent years. Reinders etc. (2003) comparatively analyzed 11 European countries, and found great differences between direct and indirect energy consumption of families [10]. Brown (2009) investigated the energy consumption carbon emissions of the transportation and construction industries of 100 major urban areas in the United States [11]. Hertwich (2009) analyzed the carbon footprint of 73 countries and 14 regions of the world [12]. Sovacool and Brown (2010) calculated and compared 12 cities of China, such as Beijing, and put forward corresponding urban planning policies and suggestions [13]. Chen, etc. (2010) studied characteristics and effect factors of urban household consumption of carbon emissions in Kunming Province of China in 2000-08, which is based on the
IPCC method. They found that the correlation between urban population and household carbon emissions is the largest [14]. Zhao (2010) roughly estimated the carbon emissions of residents' consumption in Shaanxi Province of China and simply analyzed effect factors with the ratio of residential consumption amounts in various industries [15]. The results of Feng etc. (2011) showed that China's urban resident emissions per capita were presenting an increasing trend year by year. Therein, indirect energy consumption and emissions of more than those of direct all the time, but the difference is shrinking gradually [16].

As the urbanization process continues to develop, scholars have begun to pay attention to carbon emissions in rural areas and different income families for research. Most of these kinds of research are focused on country [17-21] as well as provincial levels. Zhang (2011) studied the carbon emissions and differences between urban and rural residents, and then pointed out that a rural resident who turned into a city dweller will increase standard coal consumption by $1,085.26 \mathrm{~kg}$ [22]. Through the urban household survey data, Golley (2012) studied the demand of urban family life and $\mathrm{CO}_{2}$ emissions of China, investigated the variation degrees between living demand amounts and $\mathrm{CO}_{2}$ emissions in view of different consumption levels. The results indicated that rich families produce more emissions [23]. Qu (2013) field-surveyed the carbon emissions of northwest areas of China, and the evaluation results showed that the carbon emissions mainly come from coal, electricity, and food consumption, and are influenced by geographical environment, family size, income, and age structure [24]. Wang (2015) observed the carbon emissions of urban and rural households in China from 1995 to 2011, and found that the gap between urban and rural household carbon emissions in China is widening, but the per capita gap is narrowing [25]. The results of Zhang (2016) showed that the carbon emissions of the urban residents were larger than those of rural residents [26].

At present, the statistical methods of carbon emission research of residential consumption mainly focus on the input-output method, consumer lifestyle model (CLA), and life-cycle method (LCA). Based on these models, many scholars extend their research combined with the characteristics of their respective research fields.

LCA is a bottom-up approach to assessing carbon emissions during the phases of a product, including production, transportation, marketing, and end-of-life, and is suitable for studying micro-levels such as specific processes as well as the carbon footprint of an individual product. This model needs to delineate the entire life cycle while the boundary is difficult to define, which might make it easy to repeat the calculation, and difficult to obtain detailed data. At present, the application on carbon emissions assessment is currently focused on the calculations of carbon emissions of some products or services, and has a mature relevant standard for reference. Huppes et al. (2006) combined the environmental expansion of input-output analysis (EEIOA) with product LCA and constructed a mixed mathematical model for 
calculating the proportion of various consumer goods in the European family environment affect [27]. Weber et al. (2008) analyzed the carbon footprint of global and American households by using consumer spending surveys and multi-country LCAs [28]. Lin (2013) developed a carbon accounting method based on the actual consumption surveys and the life cycle of emission, and analyzed the case of Xiamen, a coastal city in China. The results show that household carbon emissions in Xiamen on the level of community have a significant differentiation phenomenon [29].

In the Consumer Lifestyle Approach (CLA) model, "consumer" refers to individuals or families who purchase products and services to satisfy their life needs. Lifestyle influences and determines the behavior of consumers. The purpose of this model being initially introduced is to better understand the behavior of consumers in order to develop a better public policy. Weber $\mathrm{C}$ and Perrels A (2000) modeled the impact of lifestyle on energy consumption, and quantitatively analyzed the effects of household consumption patterns and lifestyles on energy demand and carbon emissions in Germany, France, and the Netherlands [30]. Bin S and Dowlatabadi (2005) used lifestyle analysis to study the relationship among consumer behavior, energy use, and carbon dioxide emissions of the United States [31]. Based on CLA, Wei et al. (2007) quantified the direct and indirect impacts of urban and rural lifestyles on energy use and the corresponding $\mathrm{CO}_{2}$ emissions from 1999 to 2002 in China. The study indicated that about $26 \%$ of total energy consumption and $30 \%$ of $\mathrm{CO}_{2}$ emissions are caused by family life and economic activities that support such needs each year [32].

The input-output model is the most frequently used method for studying the calculation of carbon emissions, which integrates the producer and consumer perspectives into a unified accounting framework, as well as synthesizes the economic relationships between specific sectors and makes good use of total demand coefficient for associating output with input, which makes the calculation of carbon emissions during residential consumption more accurate. Lenzen (1998) used the input-output model to estimate household $\mathrm{CO}_{2}$ emissions of Australia from 1993 to 1994. The results showed that $\mathrm{CO}_{2}$ emissions would increase with household income, and his research confirmed that energy consumption and indirect $\mathrm{CO}_{2}$ emissions accounted for $65 \%$ of total energy consumption and total $\mathrm{CO}_{2}$ emissions [33]. According to the input and output table of 115 sectors of India, Pachauri and Spreng (2002) measured the indirect energy demand for households and demonstrated that the main drivers of household energy consumption growth are per-capita consumption growth, population, and energy intensity [34]. Reinders et al. (2003) compared the situations in 11 European countries with the MRIO model and found that direct and indirect household energy consumption varied widely [35]. Shui and Harriss (2006) used the input-output LCA software to calculate the indirect carbon emissions exported from America to China [36]. Park et al. (2007) analyzed the direct and indirect energy needs of households by using input-output tables and decomposed input-output tables for 19802000 in Korea [37]. Matthews et al. (2008) developed an economic input-output LCA model (EIO-LCA) to assess the carbon footprint of industries, businesses, and households [38]. Druckman et al. (2009) used the quasimulti-regional input-output (QM-RIO) model to calculate household carbon footprints in the UK from 1990 to 2004 and found that indirect carbon was the largest, followed by direct energy use, while the increasing demand for living is one of the main reasons for the rise in carbon emissions [39]. The input-output method integrates the perspectives of producer and consumer into a unified accounting framework so that the economic relationship between the specific sectors can be studied synthetically. The model, which is well correlated with the full demand coefficient, makes the emission calculation more accurate. Based on the above advantages, the input-output model has become the most popular method for studying carbon emissions.

From the literature review presented above, we can see that:

1. In the study of household carbon emissions, although the use of the input-output model is in large part filled, the data selection is comparatively long ago. According to the latest research results of Zhu L. (2016), the average carbon emission factor used in the calculation of carbon emissions is $40 \%$ lower than the default value [40]. In addition, the former usually uses the total output to calculate $\mathrm{CO}_{2}$ emission intensity when calculating indirect carbon emissions. However, since the total output of each sector includes intermediate input for other sectors, it cannot reflect a complete situation objectively and accurately of the super city Beijing - at this stage of residential carbon emissions. The life cycle method used by the predecessors is more difficult to define the boundary and to obtain some of the detailed data, so that it would easily cause repeated calculation problems. Consumer lifestyle approach requires a large number of onlooker survey data, and cannot clear the emissions of products and services.

2. Most previous studies on carbon emissions of residential consumption mainly concentrate on indirect carbon emission calculations, which ignore the research of direct carbon emissions to some extent, let alone the collaboration between direct and indirect emissions. Through joint research, we can get more detailed information about the energy consumption structure. Therefore, based on the improved inputoutput model, this paper studies the residential carbon emissions of Beijing in 2012, which aims to clarify the source and main composition of residential energy consumption that produces carbon emissions, so as to provide the appropriate policy suggestions for emission reductions, which is of great significance for the green and low carbon development of other provinces and cities. 


\section{Material and Methods}

For the calculation of indirect carbon emissions of residential consumption and the current situation of Beijing, this paper improves the original input-output model for calculation, in which the calculation of $\mathrm{CO}_{2}$ emission intensity of it uses the sector added value of the input-output table. This method gets rid of the central input value of various departments to make it more accurately reflect the indirect $\mathrm{CO}_{2}$ emissions of various departments of Beijing in 2012. For calculating indirect carbon emissions of residential consumption and the current situation of Beijing, this paper improves the original input-output model for calculation, in which the calculation of $\mathrm{CO}_{2}$ emission intensity of it uses the sectoradded value of the input-output table. This method gets rid of the central input value of various departments to make it more accurately reflect the indirect $\mathrm{CO}_{2}$ emissions of various departments of Beijing in 2012.

\section{Calculation of Direct Carbon Emissions}

Consumption of direct carbon emissions refers to the carbon emissions generated by direct energies, including residential heating, cooking, transportation, and other activities, and the energies including coal, oil, gas, and other primary energy sources, diesel and other secondary energy, as well as heat and electricity. Among them, to classify the uses of electricity and heat emissions are often complicated, especially in residential electricity. Although there are no direct emissions during its use, its upstream production consumes large amounts of fossil fuel, so it has been recognized as the main source of energy. If the classification is from the view in production and consumption, electricity and heat can usually be classified as indirect carbon emissions. However, when making household energy consumption and carbon emission studies, scholars usually range the two energies as directly sources of a household carbon footprint. According to the latest research of Liu (2016), the carbon emission coefficient of China is $40 \%$ lower than the default value, so this paper adjusts it. So, the consumption direct carbon emissions accounting equation are as follows (1):

$$
\mathrm{E}_{1}=\sum_{1}{ }_{1}^{\mathrm{i}} f \mathrm{i} \times \mathrm{Q}_{\mathrm{i}}
$$

...where $\mathrm{E} 1$ is direct carbon emissions (Unit: $\mathrm{t}$ ), fi is the $i$-th energy $\mathrm{CO}_{2}$ emission factor (Unit: $t / t$ ), $Q i$ is the $i$-th direct energy consumption (Unit: $t$ ), and i presents the type of direct energy consumption. $f$ i refers to the U.S. National Bureau of Statistics (NBS) (2011) for each energy-based carbon emission value, which is calculated as shown in Table 1.

\section{Calculation of Indirect Carbon Emissions}

The definition of residential consumption indirect carbon emissions is that, due to the people's demands for basic necessities in all aspects, the consumption of a lot
Table 1. Energy emission coefficient.

\begin{tabular}{|c|c|c|}
\hline $\begin{array}{c}\text { Energy Category } \\
\text { (TC/t standard coal) }\end{array}$ & $\begin{array}{c}\text { Heat } \\
\text { (KJ) }\end{array}$ & $\begin{array}{c}\text { Carbon emission } \\
\text { factor } \\
\text { (tc/tce) }\end{array}$ \\
\hline Raw coal & 20,908 & 0.5589 \\
\hline Coke & 28,435 & 0.8313 \\
\hline Gasoline & 43,070 & 0.8236 \\
\hline Kerosene & 43,070 & 0.8452 \\
\hline Diesel & 42,552 & 0.8626 \\
\hline Fuel oil & 41,816 & 0.8834 \\
\hline Liquefied petroleum gas & 50,179 & 0.8641 \\
\hline $\begin{array}{c}\text { Natural gas } \\
\text { Heating power (t/GJ) }\end{array}$ & 38,931 & 0.5964 \\
Electricity (t/MWh) & $/$ & 0.118 \\
\end{tabular}

Source: National Bureau of Statistics NBS (2011). Among them, the emission coefficient of electricity is from China's regional power grid baseline emission factor of 2012.

The emission coefficient of heat energy is the ratio of two parts of the energy balance in 2007 according to the Beijing Statistical Yearbook 2008. The first is the emissions that are produced by energy production when the electricity and heat are processing and conversing, the other is the energy from production.

of non-energy goods and services in which the producing, processing, transportation and consuming will consume a lot of energy and carbon for it.

Leontief, an American economist, founded inputoutput analysis in 1936, which introduced into the field of environmental economics in 1970s. The basic formula of the model (2) as follows:

$$
\mathrm{X}=(\mathrm{I}-\mathrm{A})^{-1} \times \mathrm{Y}_{\mathrm{j}}
$$

Wherein, $\mathrm{X}$ is the total output (Unit: million), $\mathrm{A}$ is a direct consumption coefficient matrix, then (I-A) ${ }^{-1}$ is the Leontief matrix, that is absolutely necessary coefficient matrix; $\mathrm{Y}^{\wedge}$ is the final consumption (Unit: million), also a diagonal matrix, where $Y_{j}$ represents the final term usage amount of $j$-th sector in products and services.

Based on the traditional input-output analysis, combined with the carbon intensity of the industry, we can conclude the following steps that are used to calculate the indirect carbon emissions.

(1) Carbon emissions of each department are calculated by the formula (3), in which a variety of energy emission coefficients shown in Table 1.

$$
\mathrm{E}_{\mathrm{c}}=\mathrm{P} \times f_{\mathrm{i}}
$$

Wherein, $\mathrm{E}_{\mathrm{c}}$ is the carbon emissions (Unit: ton); $\mathrm{P}$ is energy consumption (Unit: ton); $f_{\mathrm{i}}$ is carbon emission coefficient. (2) $\mathrm{CO}_{2}$ emissions intensities of each department are calculated by the formula (4), in which carbon emissions are calculated by the above formula (3). 


$$
\mathrm{CI}=\mathrm{E}_{\mathrm{c}} / \mathrm{VA} \times 44 / 12
$$

Wherein, $\mathrm{CI}$ is $\mathrm{CO}_{2}$ emission intensity(Unit: t/ million); EC is total carbon emissions(Unit: $\mathrm{t}$ ); $\mathrm{VA}$ is added value(Unit: million), which are from the inputoutput tables. The reason for using the added value instead of the total output is that the use of the total output will result in the repeated calculation of the intermediate input, which makes the actual calculation value too large. Thus, for overcoming the deficiency, this paper uses the added value. The constant is the conversion carbon into $\mathrm{CO}_{2}$.

(3) Calculation of indirect carbon emissions of residential consumption:

$$
\mathrm{E}_{2}=\mathrm{CI}^{\wedge} \times(\mathrm{I}-\mathrm{A})^{-1} \times \mathrm{Y}^{\wedge}
$$

Wherein, $\mathrm{E}_{2}$ represents consumption indirect emissions (Unit: $\mathrm{t}$ ); $\mathrm{CI}^{\wedge}$ behalf of the diagonal matrix of $\mathrm{CO}_{2}$ emission intensity; $\mathrm{A}$ is the direct consumption coefficient matrix of input-output model, then (I-A $)^{-1}$ is the Leontief matrix, which is absolutely necessary coefficient matrix; $\mathrm{Y}^{\wedge}$ is final consumption (unit: million), which is a diagonal matrix.

\section{Data Sources and Sector Process}

The calculation of consumption of indirect carbon emissions is based on the input-output method using the input-output table published every five years. So far, the latest input-output table is 2012, so the data source and calculation results in this study are all from 2012. The resident direct energy consumption data is from the Beijing energy balance (from the 2013 China Energy Statistical Yearbook) as well as the direct energy consumption of all industries and residential consumption expenditures.

According to the 57 departments of the Beijing Statistical Yearbook and the 42 departments in the inputoutput table of Beijing in 2012, this paper will consolidate these departments into 42 departments, as shown in Table 2.

According to the Beijing Statistical Yearbook, 08 volumes: People's livelihood, which divided the residential consumption expenditure into eight categories by the

\begin{tabular}{|c|c|c|c|}
\hline No & Final Department & No & Final Department \\
\hline 01 & Architecture & 22 & Metallurgical Smelting and Calendaring \\
\hline 02 & Accommodation and Catering & 23 & Non-metallic mineral products industry \\
\hline 03 & Chemical Products & 24 & Non-metallic minerals and other mineral products \\
\hline 04 & Coal Mining Product & 25 & Oil and gas extraction products \\
\hline 05 & Coal Mining Products & 26 & Other Manufacturing \\
\hline 06 & Comprehensive utilization of waste resources & 27 & Paper printing and cultural and educational supplies \\
\hline 07 & Culture, Sports and Entertainment & 28 & Petroleum, coking products and nuclear fuel processed goods \\
\hline 08 & Education & 29 & Public Administration, Social Security and Social Organization \\
\hline 09 & Electrical machinery and Equipment & 30 & Real estate \\
\hline 10 & Electricity, heat production and supply & 31 & Rental and business services \\
\hline 11 & $\begin{array}{l}\text { Farming, Forestry, Animal Husbandry and Fishery } \\
\text { Products and Services }\end{array}$ & 32 & $\begin{array}{l}\text { Residential conservancy, environment and public facilities } \\
\text { management }\end{array}$ \\
\hline 12 & Finance & 33 & Scientific research and technical service \\
\hline 13 & Food and Tobacco & 34 & Special Equipment \\
\hline 14 & Gas production and supply & 35 & Textiles \\
\hline 15 & General Equipment & 36 & $\begin{array}{c}\text { Telecommunication equipment, computers and other electronic } \\
\text { equipment }\end{array}$ \\
\hline 16 & Health and social work & 37 & Textile and garment footwear leather feathers and their products \\
\hline 17 & Instrument and Apparatus & 38 & Transportation Equipment \\
\hline 18 & $\begin{array}{l}\text { Information transmission, software and } \\
\text { information technology services }\end{array}$ & 39 & Transportation, warehousing and postal services \\
\hline 19 & $\begin{array}{l}\text { Metal products, machinery and equipment repair } \\
\text { services }\end{array}$ & 40 & $\begin{array}{l}\text { Water conservancy, environment and public facilities } \\
\text { management }\end{array}$ \\
\hline 20 & Metal products industry & 41 & Water production and supply \\
\hline 21 & Metal mining products & 42 & Wholesale and Retail \\
\hline
\end{tabular}

Table 2. Sectors being merged. 
Table 3. Consumption sector divisions.

\begin{tabular}{|c|c|}
\hline Consumption category & Counterparts \\
\hline Food & Food manufacturing and tobacco processing industry \\
\hline Clothing & Textile; Textile, leather and feather products industry \\
\hline $\begin{array}{c}\text { Household equipment and } \\
\text { services }\end{array}$ & $\begin{array}{c}\text { Wood processing and furniture manufacturing; } \\
\text { Electrical equipment and machinery }\end{array}$ \\
\hline Housing & $\begin{array}{c}\text { Construction; Metallic mineral products industry; } \\
\text { Fabricated metal products; Leasing and business services }\end{array}$ \\
\hline Health care & Health, social security; Social welfare \\
\hline $\begin{array}{c}\text { Transportation and } \\
\text { Communication }\end{array}$ & $\begin{array}{c}\text { Transportation equipment manufacturing communications equipment, computers and other } \\
\text { electronic equipment manufacturing industry; Transport, storage and post service; Information } \\
\text { transmission, computer services and software industry }\end{array}$ \\
\hline $\begin{array}{c}\text { Culture, education, entertainment } \\
\text { and services }\end{array}$ & $\begin{array}{c}\text { Paper printing and Educational and Sports Goods; } \\
\text { Education and culture, and sports and entertainment }\end{array}$ \\
\hline $\begin{array}{c}\text { Other goods and services } \\
\text { Accommodation and catering industry, wholesale and retail; } \\
\text { Resident services and other services }\end{array}$ & \begin{tabular}{c} 
and \\
\hline
\end{tabular} \\
\hline
\end{tabular}

urban household consumption expenditure constitutes, this paper makes a sector consumption expenditure division, we put the consumption sector into: food; clothing; household equipment and services; housing; health care; transportation; culture, education, entertainment, and services; and other goods and services for a total of eight departments, as shown in Table 3.

\section{Results and Discussion}

\section{Direct Carbon Emissions of Residential Consumption}

Main direct energy of residential consumption comes in six types: coal, gasoline, liquefied petroleum gas, natural gas, electricity, and heat. This paper put the direct carbon emissions into urban and rural areas (Fig. 1). The direct consumption of urban residents is about 18.72 million tons of carbon emissions, mainly in gasoline and heating, accounting for $40.88 \%$ and $28.37 \%$, respectively.

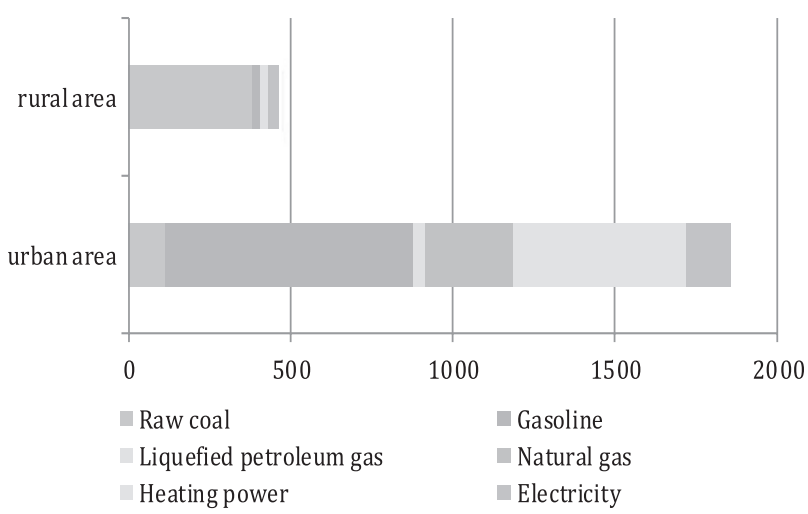

Fig. 1. Direct emissions of urban and rural areas in Beijing $(10,000$ tons $)$.
Compared to previous studies, the proportion of gasoline increased by nearly $18 \%$. Direct carbon emissions of rural residential consumption are about 4.64 million tons, which accounts for a large proportion of the coal and electricity, respectively, at $82.12 \%$ and $5.34 \%$. The direct carbon emission per capita of urban residents is about 1.05 tons per person, while the per capita direct carbon emission of rural residents is about 1.5 times that of urban per capita, which is about 1.62 tons per person.

This paper argues that the above phenomenon is mainly attributed to the following aspects:

First of all, since 2008 the Beijing municipal government has formulated and implemented policies and measures to promote energy conservation and emissions reduction, and vigorously supported the development and utilization of new energy sources such as solar, wind, geothermal, and biomass, as well as promoted alternative energy industries such as hybrid and hydrogen fuelsaving and energy-saving new technologies and products. The authorities have been strengthening motor vehicle pollution control, updating and eliminating 106,000 cars whose pollutants are over-discharged to support energy savings and environmental protection, and have even built several "green" fleets and purchased 1,000 energy-saving environmental buses. These measures have resulted in a reduction of almost 4 million tons of direct carbon emissions in 2012 compared to 2007.

Secondly, for the town, the number of vehicles is so large. There are 42 family cars and 15 bikes that use the gasoline as the main fuel (per 100 households on average). The consumption spending on cars is 106 percent over 2011, and the capacity of 2012 is $125 \%$ compared to 2011 . So the direct energy of consumption generated by the gasoline occupies the largest proportion.

Moreover, with living conditions in rural areas rapidly improving, many families have more pieces of household equipment than before, such as refrigerators, air conditioners, and other large power-consumption 
appliances. According to the Beijing Statistical Yearbook data of 2012, rural families have 103 refrigerators, 113 air conditioners, and 136 color TV sets on average, which has greatly increased in contrast to 2011. So carbon emissions caused by electrical use in the energy emissions results in a larger proportion.

For the direct consumption of urban energy - heat and in rural areas raw coal - the portion of heating system attributes a lot. Especially for rural residents, the main use of coal furnaces - a backward coal-fired heating unit - not only leads to great energy consumption and low security, but also can easily cause accidents. At the same time, the energy use of this device makes coal use far higher than other citizens. Some families also use electric heaters such as the small sun, which is currently more common as the main energy heating equipment that uses electricity. They are cheap, especially in some no heating or less heating effect rural areas. But this kind of equipment would cause large power consumption, and is only applicable for a small area of instant heating, whose heating quality and service life are difficult to guarantee. In addition to these two methods, the heating use of air-conditioning is also increasing, which the fact that the causes of power consumption cannot be underestimated.

\section{Indirect Carbon Emissions of Residential Consumption}

According to the calculations above, we ultimately obtain the indirect carbon emissions of residential consumption as shown in Fig. 2. Also, eight consumption categories of residential consumption of Beijing in 2012 are presented in Fig. 3.

Through the improved input-output model, this paper avoids the double-counting problem of the middle input parts of various industries and obtains the following results: In terms of the total amount, the carbon emissions of 42 departments in Beijing of 2012 are 3,327.373 million tons, and indirect carbon emissions amounted

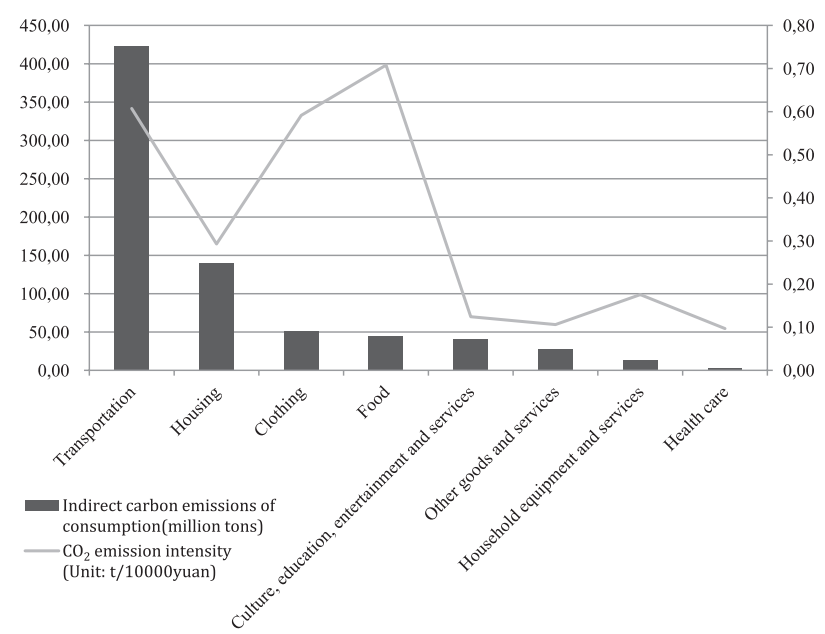

Fig. 3. Eight consumption categories of indirect carbon emissions of residential consumption.

to 739.582 million tons. According to the constitutes of indirect carbon emissions of residential consumption, it is mainly from the consumption categories of food, clothing, household equipment and services, health care, transportation and communication, culture, education, entertainment and services, housing, and other goods and services that amount to $73,958.23$ million tons. Among them, $57.2 \%$ and $18.9 \%$ of the carbon emissions are transportation and communication, respectively. Followed by clothing and food, culture, education, entertainment and services accounting for $6.9 \%, 5.9 \%$, and $5.5 \%$. Other emissions of consumption categories are relatively small, with other goods and services, household equipment and services, and health care accounting for about 3.6\%, $1.7 \%$, and $0.4 \%$, respectively. Unlike previous studies, transportation and communications and residential emissions accounted for an increase, while the proportion of food carbon emissions decreased. From the perspective of $\mathrm{CO}_{2}$ emission intensity, the highest part is food, which

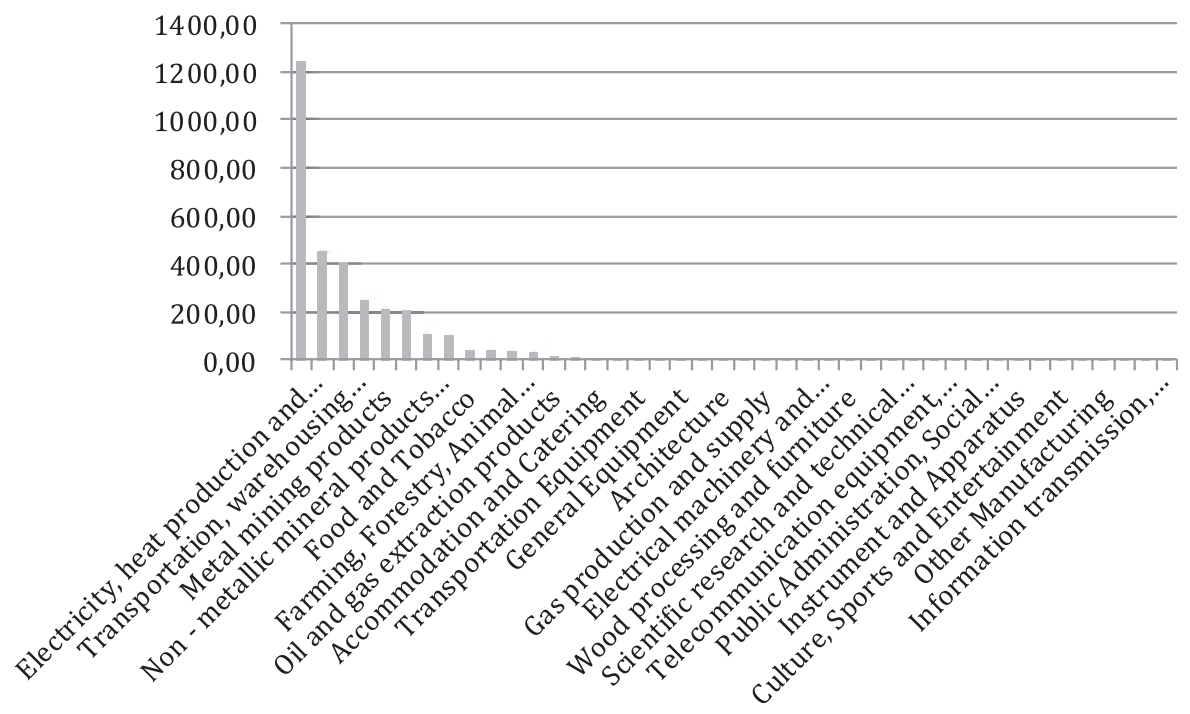

Fig. 2. Carbon emissions of 42 departments (in million tons). 
is 0.7081 tons/million, followed by transportation and communication and clothing, which is about 0.6 tons/ million.

This paper believes that the above phenomenon is mainly due to the following aspects:

High carbon emissions and the increased proportion of the transportation and communication category are due mainly to rapid economic development, including the improved living standards of residents, along with the constant modifications of urban rail transit construction and public facilities. All these reasons makes people increasingly likely to take convenient low-cost public transportation or drive private cars. Besides, more and more people choose to go out for entertainment nowadays, which results in increased times of using vehicles. These all have resulted in high levels of carbon emissions from transportation and communications.

As for the housing aspect, this paper attributes the huge influx of migrants to Beijing in recent years to the rocketing housing demand. Let alone the increasing investments in residential buildings and the requirements of more comfortable living spaces. And these superior housing and living conditions, in turn, have attracted a large population to Beijing. A cycle begins, which makes the carbon emissions of housing maintain a high level.

In the case of the highest $\mathrm{CO}_{2}$ emission intensity of food, this paper argues that the added value of unitproduced production in this sector is lower. When considering the carbon emissions per unit of GDP, namely carbon intensity, the overall carbon dioxide intensity of the food sector is relatively higher than other departments.

In summary, we can conclude that the total carbon emissions for urban and rural residents in Beijing is 762.948 million tons, of which 23.366 million tons are for direct carbon emissions and 739.582 million tons are for indirect emissions, accounting for 3\% and $97 \%$, respectively. This shows that carbon emissions of Beijing are mainly generated by the final consumption of residents. The focus of emissions reduction is indirect carbon emissions.

\section{Conclusions}

In this paper, we use the improved input-output model to change the total output of $\mathrm{CO}_{2}$ emission intensity into the added value, so that we make more accurate research on the carbon emissions of residents in Beijing in 2012. Our conclusions are:

1. In terms of direct carbon emissions, the major energies of urban and rural residents are in different types. Townsfolk mainly use gasoline and heat, whereas the conclusions of previous research were gasoline and electricity, which indicates that the carbon emissions produced by urban heating have increased substantially. The major energy consumption of village residents are coal and electricity. In addition, the direct carbon emissions per capita of the countryside is about 1.5 times higher than in town.
2. Indirect carbon emissions account for a large proportion, about $97 \%$, of total carbon emissions. It mainly consists of eight consumption categories, including food, clothing, household equipment and services, health care, transportation and communications, cultural, educational and entertainment goods and services, and housing and other goods and services. For Beijing residents, indirect carbon emissions are mainly concentrated in transportation and communications and housing, followed by food, clothing, cultural, sports, entertainment, and services. The results of available literature mainly focus on food, transportation, and communication, which shows that Beijing residents have increased their carbon emissions due to the following reasons: the higher requests for living conditions and the rising consumptions of foreign population, and the greater willingness for travel with the improvement of people's living standards.

Beijing is advancing toward being an international metropolis, along with the rapid development of urbanization and industrialization, and should pay greater attention to sustainable development between living standards of residents and the environment. The impact of consumer behavior on carbon emissions is significant, and it is essential to carry on targeted carbon reduction measures. Based on the analysis of the results, this paper puts forward some suggestions and measures from two perspectives: urban and rural areas.

\section{Urban Areas}

Given the current situation, a low-carbon consumption living pattern is required to be optimized. A town is the main area of indirect carbon emissions of consumption, while urban residential carbon emissions are mainly produced by transportation and communications, which is the most important part, and housing. In this regard, the government should increase publicity for low-carbon living and actively advocate for the low-carbon lifestyle for urban residents, and popularize the concept and benefits of low carbon so as to improve awareness of energy savings and green travel while enhancing social responsibility. In this way, consumption behavior of residents would be converted from material consumption to both material and service consumption, then gradually to sustainable consumption patterns. By giving rewards for low-carbon behavior such as the return of cash or fee remissions after reaching a certain amount of monthly transportation, the government could encourage residents to change the traditional mode of high-energy consumption, like taking public transport facilities when going out. To rectify and centrally manage pile-sharing bicycle market which is a bicycle-rental system, that is inhabitants can rent bicycles at low cost, and to subsidize the related enterprises for the corresponding costs like pre-publicity and management.

Second, we need to vigorously do more research and promote the consumption of new energy vehicles. At present, the government has given tax preferences on low- 
carbon products and subsidies for encouraging businesses and consumers of low-carbon car consumption. In 2014 the Beijing municipal government announced that personal purchases of new energy vehicles are not restricted by the license-plate lottery policy. In 2016 the Beijing Municipal Bureau of Finance and other departments jointly issued a new energy vehicle subsidy to encourage residents to buy energy-saving and new-energy vehicles. For research and development, it is recommended that the government would better set up research funds to cultivate special talents, and increase the number of charging piles to solve the inconvenience of new-energy vehicle charging problems in cities that are widely promoting new-energy vehicles.

Furthermore, the improvement of people's living standards promotes travel demand, and the number of foreign tourists is growing fast. New Year vacation and other public holidays is peak tourism, and carbon emissions are also increasing sharply in this period. We suggest that the government could build a direct sightseeing route for tourist attractions, invest in the construction of suburban railway lines and use energy-saving and new-energy buses - all of which can provide convenient, diversified, and environmentally friendly travel options for mass tourism.

For the aspect of housing, we suggest that real estate companies and design companies should increase R\&D investment, attaching importance to the training of $R \& D$ designers, building energy-efficient buildings with wind power and solar power generation facilities, and improving the utilization rate of living areas.

\section{Rural Areas}

According to the above study, it is urgent to actively promote energy-saving innovations in living facilities. The calculation results indicate that residential consumption of natural gas, electricity, and other energy sources are at a relatively low level, so the government could improve the structures of household energy use as well as increase input to new energy motor R\&D through tax relief and subsidies in order to indirectly optimize the residential energy consumption structure.

In the study of direct carbon emissions, we found that carbon emissions generated by urban heat and rural heating is huge. Nowadays, natural gas has been relatively common in cities, while gas boilers have become increasingly popular as household independent heating equipment. Although natural gas is still not popular in the countryside, there are biogas systems that can be used as gas heating. Straw gas stoves, turning waste into treasure as a free "liquefied gas" for peasants, is an economic heating apparatus that uses plant fuel to produce a flammable gas through the gas furnace under confined hypoxia conditions by using dry distillation pyrolysis and thermal oxidation. The advantage of this heating device is that the cost is very low and it is more economical and practical for some rural areas that have many straws, while the shortcomings are the tar pollution produced by the straw gasifier and the inconvenience of equipment maintenance. Another heating method is using electricity, but its popularity is limited due to high cost. Compared to coal-fired and electric heating, gas heating is more economical and environmentally friendly. Therefore, rural residents are strongly encouraged to use straw gas and renewable energy, such as solar and biomass, which not only optimize the energy structure, but also reduce the cost of residential energy consumption. This paper strongly recommends that construction firms install underfloor heating in a wide range of buildings to warm residents. This heating method can achieve low-temperature heating, save more energy, and is a benefit of the development of the low-carbon lifestyle.

\section{Acknowledgements}

The authors express their sincere thanks for support from the National Natural Science Foundation of China under grant No. 71173200 and as a National Science and Technology Major Project under grant No. 2016ZX05016005-003.

\section{References}

1. The Twelfth Five-Year Plan [J]. 2011.

2. WU K.J., GUO X., WANG W. Empirical analysis on carbon emissions of residents consumption in Shanghai[J]. Resources and Environment in the Yangtze Basin, 5, 002, 2013.

3. ABID M. The close relationship between informal economic growth and carbon emissions in Tunisia since 1980: The (ir) relevance of structural breaks[J]. Sustainable Cities and Society, 15, 11, 2015.

4. BURKE P.J., SHAHIDUZZAMAN M., STERN D.I. Carbon dioxide emissions in the short run: The rate and sources of economic growth matter [J]. Global Environmental Change, 33, 109, 2015.

5. DESTEK M.A. Renewable energy consumption and economic growth in newly industrialized countries: Evidence from asymmetric causality test $[\mathrm{J}]$. Renewable Energy, 95, 478, 2016.

6. ERDALG, ERDAL H., ESENGUN K. The causality between energy consumption and economic growth in Turkey[J]. Energy Policy, 36 (10), 3838, 2008.

7. RAMANATHAN R. A multi-factor efficiency perspective to the relationships among world GDP, energy consumption and carbon dioxide emissions [J]. Technological Forecasting and Social Change, 73 (5), 483, 2006.

8. SALAHUDDIN M., GOW J. Economic growth, energy consumption and $\mathrm{CO}_{2}$ emissions in Gulf Cooperation Council countries [J]. Energy, 73, 44, 2014.

9. TANG C.F., TAN B.W., OZTURK I. Energy consumption and economic growth in Vietnam [J]. Renewable and Sustainable Energy Reviews, 54, 1506, 2016.

10. REINDERS A., VRINGER K., BLOK K. The direct and indirect energy requirement of households in the European Union [J]. Energy Policy, 31 (2), 139, 2003.

11. BROWN M.A., SOUTHWORTH F., SARZYNSKI A. The geography of metropolitan carbon footprints $[\mathrm{J}]$. Policy and Society, 27 (4), 285, 2009. 
12. HERTWICH E.G., PETERS G.P. Carbon footprint of nations: A global, trade-linked analysis [J]. Environmental science \& technology, 43 (16), 6414, 2009.

13. SOVACOOL B.K., BROWN M.A. Twelve metropolitan carbon footprints: A preliminary comparative global assessment [J]. Energy policy, 38 (9), 4856, 2010.

14. CHEN Q., ZHENG Y.X., CHEN Y.B. Analysis of characteristics and influencing factors of carbon emissions with urban family consumption in Kunming city[J]. Environmental Science Survey, 29 (5), 14, 2010.

15. ZHAO S.Y., YOU H.J. Analysis on effect of Shanxi resident consumption to carbon emissions [J]. Sci-tech Innov Product, 5, 58, 2010.

16. FENG L., LIN T., ZHAO Q.J. Research advances on household energy consumption and household carbon footprint[J]. Ecological Science, 29 (2), 161, 2010.

17. BHATTACHARYA M., PARAMATI S.R., OZTURK I. The effect of renewable energy consumption on economic growth: Evidence from top 38 countries[J]. Applied Energy, 162, 733, 2016

18. YAO L., LIU J.R., WANG R.S. Comparison and analysis of carbon emissions embodied in household consumption between urban and rural area of China [J]. China Population Resources and Environment, 21 (4), 25, 2011.

19. GOLLEY J., MEAGHER D., MENG X. Chinese urban household energy requirements and $\mathrm{CO}_{2}$ emissions[J]. China's Dilemma: Economic Growth, the Environment and Climate Change, 334, 2008

20. ZHU Q., PENG X.Z., LU Z.M. Calculation and analysis on carbon emissions from household energy consumption in China[J]. Journal of Safety and Environment, 2, 72, 2011.

21. LIU L.C., WU G., WANG J.N. China's carbon emissions from urban and rural households during 1992-2007[J]. Journal of Cleaner Production, 19 (15), 1754, 2011.

22. ZHANG X., NIU S.W., ZHAO C S. The study on household Energy consumption and carbon emissions in China's urbanization[J]. China Soft Science, 9, 65, 2011.

23. GOLLEY J., MENG X. Income inequality and carbon dioxide emissions: the case of Chinese urban households[J]. Energy Economics, 34 (6), 1864, 2012.

24. QU J.S., ZHANG Z.Q., ZENG J.J. Household carbon emission differences and their driving factors in Northwestern China[J]. Chinese Science Bulletin, 58 (3), 260, 2013.

25. WANG L., QU J.S., LIU L.N. Analysis and comparison of urban and rural household carbon emissions in China[J]. Journal of Arid Land Resources and Environment. 29 (5), 6, 2015.
26. ZHANG Y.F., ZHANG H.Y. Calculation and analysis on carbon emissions of residents' consumption in Shaanxi province[J]. Journal of Shaanxi Normal University (Natural Science Edition), 44 (2), 98, 2016.

27. HUPPES G., KONINGA., SUH S. Environmental Impacts of Consumption in the European Union: High Resolution InputOutput Tables with Detailed Environmental Extensions[J]. Journal of Industrial Ecology, 10 (3), 129, 2006.

28. WEBER C.L., MATTHEWS H.S. Quantifying the global and distributional aspects of American household carbon footprint[J]. Ecological Economics, 66 (2), 379, 2008.

29. LIN T., YU Y., BAI X. Greenhouse gas emissions accounting of urban residential consumption: a household survey based approach[J]. PloS one, 8 (2), e55642, 2013.

30. WEBER C., PERRELS A. Modeling lifestyle effects on energy demand and related emissions[J]. Energy Policy, 28 (8), 549, 2000.

31. BIN S., DOWLATABADI H. Consumer lifestyle approach to US energy use and the related $\mathrm{CO}_{2}$ emissions[J]. Energy policy, 33 (2), 197, 2005.

32. WEI Y.M., LIU L.C., FAN Y. The impact of lifestyle on energy use and $\mathrm{CO}_{2}$ emission: an empirical analysis of China's residents[J]. Energy policy, 35 (1), 247, 2007.

33. LENZEN M. Primary energy and greenhouse gases embodied in Australian final consumption: an input-output analysis[J]. Energy policy, 26 (6), 495, 1998.

34. PACHAURI S., SPRENG D. Direct and indirect energy requirements of households in India[J]. Energy policy, 30 (6), 511, 2002.

35. REINDERS A., VRINGER K., BLOK K. The direct and indirect energy requirement of households in the European Union[J]. Energy Policy, 31 (2), 139, 2003.

36. SHUI B., HARRISS R.C. The role of $\mathrm{CO}_{2}$ embodiment in US-China trade[J]. Energy policy, 34 (18), 4063, 2006.

37. PARK H.C., HEO E. The direct and indirect household energy requirements in the Republic of Korea from 1980 to 2000 - An input - output analysis[J]. Energy Policy, 35 (5), 2839, 2007.

38. MATTHEWS H.S., HENDRICKSON C.T., WEBER C.L. The importance of carbon footprint estimation boundaries[J]. Environmental science \& technology, 42 (16), 5839, 2008.

39. DRUCKMAN A., JACKSON T. The carbon footprint of UK households 1990-2004: a socio-economically disaggregated, quasi-multi-regional input-output model[J]. Ecological economics, 68 (7), 2066, 2009.

40. LIU Z., GUAN D., WEI W. Reduced carbon emission estimates from fossil fuel combustion and cement production in China[J]. Nature, 524 (7565), 335, 2015. 